\title{
Presentación
}

\section{Nuevas dinámicas familiares}

\section{Julieta Quilodrán* y Teresa Castro**}

Hasta fines del siglo pasado los estudios dedicados al tema de la nupcialidad y más ampliamente, a la formación de las uniones conyugales, habían puesto en evidencia la marcada estabilidad de este fenómeno. ${ }^{1}$ Sin embargo la lenta evolución de éste, en comparación con la rápida disminución de la mortalidad y luego de la fecundidad, comienza a mostrar atisbos de cambio en la última década del siglo. Las especificidades en la formación de las parejas y su disolución por países, grupos sociales, características socioeconómicas y residenciales persisten, pero ocurren a distintos ritmos configurando escenarios familiares cada vez más variados.

Las familias latinoamericanas han iniciado el siglo XXI en un sutil equilibrio entre la continuidad y el cambio. La microsolidaridad familiar siempre ha tenido un importante protagonismo en la región, supliendo las carencias de unos sistemas de protección social por lo general débiles y de limitada cobertura. En la actualidad el núcleo familiar continúa siendo la principal fuente de solidaridades, reciprocidades y afectos, pero las fronteras que delimitan los vínculos familiares son cada vez más imprecisas, inestables y versátiles. La diversificación de las trayectorias conyugales y reproductivas está transformando no sólo el curso de vida de los individuos, sino también las responsabilidades familiares, los patrones de relaciones de género y las condiciones de bienestar de mujeres, hombres y niños. De ahí la importancia de medir, explicar e interpretar las múltiples facetas del cambio familiar.

En esta tarea la demografía nos proporciona herramientas muy útiles para detectar tendencias de cambio, modelizar factores causales y mostrar divergencias en los patrones de comportamiento según el género, la generación o el estrato social. Sin embargo, para avanzar

* Profesora investigadora del Centro de Estudios Demográficos, Urbanos y Ambientales de El Colegio de México. Correo electrónico: jquilo@colmex.mx.

** Centro de Ciencias Humanas y Sociales, CSIC. Correo electrónico: teresa.castro@ cchs.csic.es.

${ }^{1} \mathrm{Al}$ final de esta presentación incluimos una bibliografía con trabajos de índole demográfica sobre nupcialidad en América Latina publicados hasta 1990.

ESTUDIOS DEMOGRÁFICOS Y URBANOS, VOL. 24, NÚM. 2 (71), 2009, 283-291 
en la comprensión de las transformaciones familiares, la atribución de significados y la anticipación del curso futuro de las relaciones familiares son precisas las aportaciones de un amplio espectro de ciencias sociales y se requiere un continuo diálogo interdisciplinar.

Si la disociación entre sexualidad y reproducción, con el consiguiente descenso de la fecundidad, fue uno de los grandes catalizadores del cambio familiar en la segunda mitad del siglo Xx, la creciente informalidad, transitoriedad y fragilidad de los vínculos conyugales y paterno-filiales seguramente será uno de los ejes que moldearán las biografías familiares en el presente siglo. A diferencia de otras sociedades, la formación de uniones consensuales, las rupturas de pareja, las familias reensambladas y la fecundidad extramatrimonial no son patrones novedosos en el contexto latinoamericano, sino parte integrante del sistema familiar desde hace siglos. Sin embargo, en las últimas décadas se ha afianzando la disociación entre matrimonio y reproducción, ha aumentado la inestabilidad de las uniones y, como secuela, la figura del padre ausente, intensificando muchos de los riesgos ya existentes de vulnerabilidad social, en un contexto donde estructura familiar y desigualdad de oportunidades están estrechamente vinculados.

El significado de estos procesos de cambio familiar es ambivalente y puede interpretarse en distintas claves, muchas veces antagónicas. El aumento de la ruptura conyugal, por ejemplo, puede interpretarse como indicio del debilitamiento de lazos familiares y por tanto como una merma de capital social, pero también como la expresión de una mayor libertad de elección personal frente a las presiones económicas, religiosas o sociales. Asimismo, el aumento de uniones consensuales puede ser interpretado como expresión de responsabilidad condicionada y compromiso limitado, pero también como reafirmación de autonomía personal frente a formalismos institucionales, o como una estrategia adaptativa a la incertidumbre económica o biográfica.

Esta ambivalencia de significados y connotaciones guarda estrecha relación con el actual debate sobre la validez de la segunda transición demográfica como marco interpretativo de la evolución familiar reciente en América Latina. ¿Muestran las pautas contemporáneas una nueva forma de entender las relaciones conyugales y familiares o expresan la continuidad de patrones tradicionales? ¿Reflejan un mayor abanico de opciones vitales y familiares para el conjunto de la población o, por el contrario, favorecen sólo a los sectores privilegiados? ¿Indican un rechazo a la injerencia institucional en el ámbito privado o el des- 
interés por unas reglamentaciones percibidas como irrelevantes en lo que concierne a la protección social? En realidad no hay una respuesta unívoca. La heterogeneidad entre países y la gran desigualdad social dentro de cada uno de ellos permite la coexistencia de patrones nuevos y tradicionales, y que el mismo comportamiento sociodemográfico, como por ejemplo la consensualidad de las uniones, pueda interpretarse en clave de autonomía personal o en clave de exclusión. Sin duda el grado de desigualdad de género asociado a las distintas pautas familiares se perfila como el elemento central a la hora de diferenciar entre cambios y continuidades, entre una consensualidad de tipo moderno o de tipo secular.

Independientemente del marco interpretativo que se elija, es importante señalar que las sociedades latinoamericanas no sólo están insertas en unas tendencias de cambio familiar a escala global, sino que, al igual que otras muchas sociedades, están también expuestas a los riesgos asociados a estas tendencias. Numerosos autores advierten de los nuevos frentes de vulnerabilidad que el cambio familiar puede abrir, sobre todo si la informalidad del vínculo conyugal se traduce en desprotección y en disminución de la responsabilidad paterna. Por ello es importante que los marcos legales e institucionales continúen adecuándose para responder a la variedad de modelos de familia que se están instaurando y que se diseñen políticas efectivas que atenúen la desigualdad social ligada a las transformaciones de la estructura familiar, que garanticen el bienestar de los niños independientemente del tipo de hogar en el que convivan, y que eviten la feminización, juvenilización o infantilización de la pobreza.

El propósito de este volumen es difundir nuevas investigaciones que ilustren la diversificación de las dinámicas familiares. Los artículos reunidos en este número especial abordan el análisis de importantes dimensiones del cambio familiar, como el aumento de la consensualidad y la inestabilidad conyugal en los países del Cono Sur, la reorganización de los vínculos de parentesco y las responsabilidades familiares que implican las segundas nupcias, las relaciones de género en las parejas de distinta nacionalidad y la emergencia de cambios culturales en el significado de la paternidad. Aunque desde ópticas diferentes, todos los artículos ponen de manifiesto la creciente pluralidad y complejidad de los procesos de formación y reorganización familiar y nos brindan una valiosa reflexión sobre sus múltiples significados y causas subyacentes. Son también un magnífico exponente de la manera en que el investigador puede utilizar de manera imaginativa, además de 
las fuentes convencionales -censos, estadísticas vitales- otras como son las encuestas de hogares, entrevistas en profundidad, análisis de manuales y archivos; sobre todo cuando no dispone de encuestas del tipo WFS o DHS y de la cauda de información que éstas han proporcionado para el estudio de la formación y estabilidad familiar en el resto de los países de la región. El esfuerzo realizado en relación con la información conjuntamente con las metodologías -cuantitativas y cualitativas-y las perspectivas utilizadas -transversales y longitudinales-, han hecho posible abordar el estudio del cambio familiar.

El artículo de Wanda Cabella presenta un análisis minucioso y una interpretación sugerente y llena de matices de las tendencias contemporáneas en el ámbito de las relaciones conyugales y reproductivas en Uruguay. Su reflexión constituye una importante contribución al debate contemporáneo sobre la validez del enfoque de la segunda transición demográfica para interpretar la evolución reciente de las trayectorias familiares en ese país y en la región. Sin renunciar a integrar las especificidades históricas, socioeconómicas, culturales e institucionales del contexto regional en la explicación de las continuidades y cambios familiares, la autora no descarta vincular los nuevos escenarios conyugales y reproductivos en los países del Cono Sur a un proceso más global de erosión del modelo de familia tradicional, ligado en parte a crecientes aspiraciones de autonomía individual y de igualdad de género, y a la pérdida de legitimidad de las instituciones políticas y religiosas a la hora de regular la vida privada. Advierte, sin embargo, que los procesos de cambio familiar no son uniformes ni análogos en su significado en todo el espectro social. En este sentido la autora presenta evidencias de polarización social en el calendario de las transiciones familiares en función del nivel educativo y la posición laboral, y advierte de las nuevas vulnerabilidades asociadas a la creciente fragilidad de los vínculos familiares.

La heterogeneidad de significados atribuibles a los cambios recientes en los procesos de formación familiar es también uno de los ejes centrales del artículo de Benoît Laplante y María Constanza Street. Los autores analizan los factores sociales y económicos que están asociados con la probabilidad de estar en una unión consensual en Argentina, así como los factores que inciden en las trayectorias posteriores de formalización legal, ilustrando la coexistencia de diversos tipos de unión con significados, antecedentes y destinos diferentes. También documentan un importante aumento de la consensualidad conyugal en las clases medias urbanas, que en el pasado permanecían ajenas a 
esta práctica. Aportan, en definitiva, múltiples ángulos de explicación al aumento reciente de las uniones consensuales, incluyendo la persistencia de prácticas seculares, las recientes condiciones de incertidumbre económica y la reducción de la brecha respecto a formas conyugales entre estratos educativos.

Las migraciones internacionales son un elemento integral del paisaje contemporáneo de globalización que añade complejidad a las estructuras, formas de organización y relaciones familiares, creando un complejo entramado de vínculos transnacionales. Asimismo, las migraciones internacionales son importantes agentes de cambio en los procesos de formación familiar en el lugar de destino, erosionando los patrones tradicionales de endogamia y ejerciendo una influencia específica en las pautas de homogamia conyugal y en la división intrafamiliar de roles. El artículo de Clara Cortina, Thaís García y Albert Esteve aborda la intersección entre migración, nupcialidad y ocupación desde una perspectiva de género. Utilizando las pautas de homogamia por edad y nivel educativo y la prevalencia de familias de doble ingreso entre las parejas mixtas en España, como indicadores indirectos de las relaciones de género intrafamiliares, los autores documentan importantes diferencias según el tipo de unión -matrimonial o consensual- y según la combinación de orígenes de los cónyuges. Los resultados de su análisis nos muestran que las uniones entre dos inmigrantes son las que presentan una mayor prevalencia de doble ingreso, mientras que en las uniones mixtas -entre las que predominan las parejas de cónyuge español y cónyuge latinoamericano-, la prevalencia de doble ingreso disminuye.

La diversificación de trayectorias conyugales y la creciente complejidad de vínculos y redes familiares se ponen especialmente de manifiesto en las segundas nupcias. El artículo de Glaucia dos Santos Marcondes aborda el fenómeno de la recomposición familiar desde una perspectiva cualitativa, y nos ofrece una estimulante reflexión sobre la redefinición de redes de parentesco, de derechos y obligaciones con respecto a núcleos familiares anteriores, de proyectos reproductivos, de lealtades y prioridades, que supone la formación de segundas o terceras uniones. Estos nuevos proyectos conyugales y reproductivos, aunque no exentos de ambigüedades y tensiones, reflejan la maleabilidad de la institución familiar e ilustran las fronteras elásticas y cambiantes de las relaciones familiares.

La progresiva democratización de la vida cotidiana familiar, tanto en el ámbito de las relaciones conyugales como en el de las relaciones 
paterno-filiales, ha sido un proceso lento y no exento de contradicciones y conflictos. Las estructuras jerárquicas que tradicionalmente definían la posición de los miembros de la familia en función del género y la generación se han ido desdibujando tanto en el terreno normativo como en el de los comportamientos, y es de sumo interés analizar los cambios culturales que han propiciado este proceso. El artículo de Isabella Cosse aborda la emergencia de un nuevo modelo de paternidad, menos autoritario y más dialogante, durante el periodo 1950-1975 en Argentina. Mediante el análisis de manuales de puericultura, revistas, comedias familiares en radio y televisión, y materiales de archivo, la autora examina la gestación de un nuevo modelo familiar que exigía de los padres un mayor compromiso con el cuidado y la atención afectiva de sus hijos, que redefinía la identidad masculina y la paternidad, y que preconizaba la reconfiguración de los roles de género en el ámbito familiar. El estudio refleja el importante papel de los medios de comunicación de masas en la difusión de nuevos valores familiares, estilos de socialización y patrones de conducta. Asimismo pone de manifiesto los desconciertos, tensiones y resistencias que generan los cambios culturales que trastocan las relaciones de autoridad y poder en el ámbito familiar.

En síntesis, los artículos que reúne este volumen suponen una importante contribución al estudio de las transformaciones familiares en América Latina. No sólo documentan importantes procesos de cambio en las dinámicas de formación familiar -como en el caso de Argentina y Uruguay que experimentaron una transición demográfica temprana y cuyas características los coloca hoy en una situación cercana a la de los países donde la segunda transición demográfica está más consolidada- y nos introducen en el mundo de las relaciones intrafamiliares, utilizando fuentes de datos y metodologías innovadoras, sino que nos ofrecen también múltiples lecturas e interpretaciones de estos procesos. Confiamos en que serán de interés y fuente de inspiración para una amplia audiencia.

\section{Selección bibliográfica sobre nupcialidad en América Latina anterior a 1990}

Arretx C. (1971), "Nuptiality in Latin America", en International Union for the Scientific Study of Population, International Population Conference, London, 1969, vol. 3, Lieja, IUSSP, pp. 2127-2152. 
Berquo, E. (1987), "Nupcialidade da populacao negra no Brasil”, Textos Nepo, núm. 11, pp. 7-45.

Camisa, Z. (1971), La nupcialidad femenina en América Latina durante el periodo intercensal 1950-1960, San José, Costa Rica, Centro Latinoamericano de Demografía.

Camisa, Z. (1977), "La nupcialidad de las mujeres solteras en América Latina", San José, Costa Rica, Centro Latinoamericano de Demografía (Serie A, núm. 1034).

Caravallo, A.L. (1964), "Tablas de mortalidad y de nupcialidad de Puerto Rico, 1959 y 1960”, Santiago de Chile, Centro Latinoamericano de Demografía.

Catasús, S. (1991), La nupcialidad cubana en el siglo XX, La Habana, Centro de Estudios Demográficos, Universidad de la Habana.

Downing D.C. y D. Yaukey (1979), "The Effects of Marital Dissolution and Remarriage on Fertility in Urban Latin America”, Population Studies, vol. 33, núm. 3. pp. 537-547.

Ebanks, G.E. y E. Loaiza (1989), "Nuptiality and Fertility in the Dominican Republic”, Journal of Biosocial Science, vol. 21, núm. 1, pp. 71-82.

Florez, C.E. y N. Goldman (1980), An Analysis of Nuptiality Data in the Colombia NationalFertility Survey, Voorburg, International Statistical Institute (World Fertility Survey Scientific Report, 11).

Goldani, A.M. y L. Rodríguez (1981), "Padroes e tendencias da nupcialidade no Brasil”, en Anais Segundo Encontro Nacional, São Paulo, Associacao Brasileira de Etudos Populacionais (ABEP), pp. 343-415.

Goldman, N. (1984), "Changes in Widowhood and Divorce and Expected Durations of Marriage”, Demography, vol. 21, núm. 3, pp. 297-307.

Henriquez, M.E. (1989), "Legal and Consensual Unions: their Fertility Implications in Latin America”, en Nuptiality and Ferility, Lieja, International Union for the Scientific Study of Population (IUSSP), pp. 163-174.

Jourdain, A. y J. Quilodrán (1974), “Análisis de la nupcialidad legal por generaciones en México, 1922-1969”, Demografía y Economía, vol. 8, núm. 2 (23), pp. 187-202.

Juárez, F. (1990), "La vinculación de eventos demográficos: un estudio sobre los patrones de nupcialidad”, Estudios Demográficos y Urbanos, vol. 5, núm. 3 (15), pp. $453-477$.

Levy, M.S. y M.C. de Oliveira (1977), "Tipos de uniao e padroes de casamento. 1. Consideracoes sobre tipo de uniao: aspectos institucionais e domographicos", en E.S. Berquo, M.C. de Oliveira y C.P. de Camargo C.P. (eds.), A fecundidade em Sao Paulo: caracteristicas demograficas, biologicas e socioeconomicas, São Paulo, Editora Brasileira de Ciencias, pp. 55-86.

Marin, M.A. (1981), "Les unions consensuelles en Amerique Latine: l'Amerique Centrale “, en J. Dupaquier, E. Helin, P. Laslett, M. Livi-Bacci y S. Sogner (eds.) (1981), Marriage and Remarriage in Populations of the Past, Nueva York, Academic Press, pp. 111-126. 
McCaa, R. (1994), Marriageways in Mexico and Spain 1500-1900. Continuity and Changes, Cambridge, Cambridge University Press, pp. 11-43.

Mina, A. (1980), "Aplicación del modelo estándar de nupcialidad de A.J. Coale al caso de México”, Demografía y Economía, vol. 14, núm. 4 (44), pp. 421-446.

Ojeda de la Peña, N. (1986), "Separación y divorcio en México: una perspectiva demográfica”, Estudios Demográficos y Urbanos, vol. 1, núm. 2 (2), pp. 227-265.

Ojeda, M. (1961). Tabla de nupcialidad femenina para la República de Colombia 1951, Santiago, Chile, Centro Latinoamericano de Demografía.

Pavón, P. (1990), "El mercado matrimonial en desbalance, el caso de México 1980 ”, Estudios Demográficos y Urbanos, vol. 5, núm. 3 (15), pp. 503-533.

Pebley, A.R., y N. Goldman (1986), "Legalización de uniones consensuales en México”, Estudios Demográficos y Urbanos, vol. 1, núm. 2 (2), pp. 267-290.

Potter, J. y N. Ojeda (1984), "El impacto sobre la fecundidad de las disolución de primeras uniones", en Los factores del cambio demográfico en México, México, Instituto de Investigaciones Sociales, UNAM/Siglo XXI, pp. 206-218.

Quilodrán, J. (1974), "Evolución de la nupcialidad en México, 1900-1970", Demografía y Economía, vol. 8, núm. 1 (22), pp. 34-49.

Quilodrán, J. (1979), "La nupcialidad en las áreas rurales de México", Demografía y Economía, vol. 13, núm. 3 (39), pp. 263-316.

Quilodrán, J. (1980), "Tablas de nupcialidad para México”, Demografía y Economía, vol. 14, núm. 1 (41), pp. 27-67.

Quilodrán, J. (1983), “Análisis de la nupcialidad a través de la historia de uniones”, en R. Benítez y J. Quilodrán (comps.), La fecundidad rural en México, México, El Colegio de México/UnAM, pp. 115-138.

Quilodrán, J. (1985), "Modalités de la formation et évolution des unions en Amérique Latine", en International Population Conference, IUSSP, Florencia, pp. 269-280.

Quilodrán, J. (1989), "México: diferencias de nupcialidad por regiones y tamaños de localidad", Estudios Demográficos y Urbanos, vol. 4, núm. 3 (12), pp. 595-613.

Quilodrán, J. (1989), "México: diferencias de nupcialidad por regiones y tamaños de localidad”, Estudios Demográficos y Urbanos, vol. 1, núm. 2 (2), pp. 595-613.

Quilodrán, J. (1990), "Entrance into Marital Union and into Motherhood by Social Sectors", en M. Bronfman, B. García, F. Juárez, O. de Oliveira y J. Quilodrán, Social Sectors and Reproduction in México, Nueva York, DHS/ The Population Council, pp. 4-8.

Quilodrán, J. (1992), "La vida conyugal en América Latina, contraste y semejanzas”, en Actas de la conferencia sobre el poblamiento de las Américas, vol. 3, Veracruz, IUSSP, pp. 245-264.

Quilodrán, J. (1992), "Peculiarities of Border Marriage Patterns”, en Weeks y 
Ham-Chande (eds.), Demographic Dynamics of U.S.-México Border, El Paso, Texas, The University of Texas/Western Press, pp. 89-103.

Rosero Bixby, L. (1978), "Nupcialidad y exposición al riesgo de embarazo en Costa Rica”, Notas de Población, vol. 6, núm. 17, pp. 33-62.

Rosero Bixby, L. (1978), La nupcialidad y fecundidad en cuatro zonas rurales de América Latina, San José, Costa Rica, Centro Latinoamericano de Demografía.

Samuel, O. (1990), Structures familiales et nuptialité au Mexique. Deux etudes de cas: les états d'Aguascalientes et de Veracruz, París, Centre de Recherche et de Documentation sur l'Amérique Latine.

Yaukey, D, T. Thorsen y A.T. Onaka (1972), "Marriage at an Earlier than Ideal Age in Six Latin American Capital Cities”, Population Studies, vol. 26, núm. 2, pp. 263-272. 